\title{
Effect of Neuraminidase Treatment of Rat Thymocytes on Rosette Formation with Guinea Pig Erythrocytes
}

\author{
Hiroko OKa, Shuhei Kimura, and Yoshihiro Kinoshita \\ Department of Physiology, Osaka City University Medical School, \\ Abeno-ku, Osaka, 545 Japan
}

\begin{abstract}
Summary In rat thymocytes, the effect of neuraminidase on rosette formation with guinea pig erythrocytes was studied. In medullary thymocytes, the percentage of rosette formation increased significantly after neuraminidase treatment. Some parts of receptors for rosette formation in thymocytes might be masked by sialic acid in the course of maturation.
\end{abstract}

Key Words: rosette formation, rat thymocytes, neuraminidase.

Since the report on the spontaneous rosette formation of rat thymocytes with guinea pig red blood cells (RBC) (TAKEICHI and BoONE, 1976), the biological characteristics of this rosette have been investigated. It has been demonstrated that non-heated fetal calf serum (FCS) is required for this rosette formation and that thymocytes have receptors not for guinea pig RBC but for some factors in FCS. Rosette forming cells (RFC) are considered to be cortical thymocytes because of their sensitivity towards irradiation and cortisone treatment (ELFENBEIN and Santos, 1978). Most cortical thymocytes, which are functionally immature lymphocytes, have the ability to form rosette; medullary thymocytes collected from cortisol-treated rats, that is, relatively mature lymphocytes, hardly have the ability. It was shown by using tissue rosetting method for a frozen section of thymus that RFC exist in the cortex, not in the medulla of the thymus (TAKÁcs et al., 1981). It was, therefore, assumed that the rosette-forming ability of thymocytes tended to disappear in the course of maturation, or that medullary thymocytes might be a quite different subpopulation from cortical RFC. On the other hand, it has been shown that sialyltransferase activity and sialic acid level change in the course of maturation of T cell population (DESPONT et al., 1975). In the present study, we investigated the effect of removal of sialyl residue from thymocytes surface by neuraminidase on their rosette-forming ability.

Rosette forming procedure was in accordance with the method of

Received for publication June 4, 1984

岡 博子, 木村修平, 木下喜博 
Elfenbein (ELFENBein and Winkelstein, 1978). Adult (6 to 8 weeks old, male) Wistar rats were sacrificed under ether anesthesia. Thymus glands and cervical lymph nocies were removed and finely minced with scissors. They were gently pressed between two glass slides and single cell suspension was made. Cells were washed three times in phosphate buffered saline (PBS) and diluted to $4 \times$ $10^{8}$ cells $/ \mathrm{ml}$ in PBS. Blood was taken by cardiac puncture of Hartley guinea pig with a heparinized syringe. The RBC were washed three times and diluted to $1 \times 10^{8}$ cells $/ \mathrm{ml}$ in PBS. One milliliter of lymphocyte suspension was mixed with an equal volume of RBC suspension and $0.2 \mathrm{ml}$ of non-heated FCS was added to the mixture. The resulting material was incubated at $22^{\circ} \mathrm{C}$ for $30 \mathrm{~min}$, centrifuged at $100 \mathrm{~g}$ for $5 \mathrm{~min}$, and incubated again at $4^{\circ} \mathrm{C}$ for $60 \mathrm{~min}$. The sediment was stirred, a drop of the suspension was put onto a glass slide, and 200 nucleated cells were observed with a phase-contrast microscope. Lymphocytes binding to more than three RBC were considered to be RFC.

Neuraminidase treatment was performed as follows. Various amounts of solution of neuraminidase from Vibrio cholerae were added to $1 \mathrm{ml}$ of cell suspension. The enzyme preparation had the ability of 1 unit/ml and was used as a solution containing $0.01 \mathrm{unit} / \mathrm{ml}$ in PBS. The lymphocyte suspension and guinea pig $\mathrm{RBC}$ suspension were separately incubated with neuraminidase for $30 \mathrm{~min}$ at $37^{\circ} \mathrm{C}$, washed three times in PBS, and placed in a rosette forming assay. Cortisol-treated rats received intramuscular injection of hydrocortisone acetate $(0.2$ $\mathrm{mg} / \mathrm{g}$ of body weight) and were sacrificed 3 days later for the experiment.

The results are presented in Fig. 1. Open circles indicate whole thymocytes treated with neuraminidase. The mean percentage \pm S.D. of RFC before the enzyme treatment was $73.2 \pm 3.9 \%$. A maximum enhancement up to $85.5 \pm 4.7 \%$ was observed at the enzyme concentration of $4 \times 10^{-3}$ unit $/ \mathrm{ml}$. This increase was statistically significant. Closed circles indicate thymocytes collected from cortisol-treated rats. Before neuraminidase treatment, they rarely formed rosette with guinea pig RBC. The mean percentage \pm S.D. of RFC was $2.8 \pm 2.0 \%$. After the enzyme treatment of this population, a marked increase of RFC percentage to $15.1 \pm 6.7 \%$ was observed at a concentration of $2 \times 10^{-3}$ unit $/ \mathrm{ml}$. Further enhancing effects were observed at concentrations greater than $4 \times 10^{-3}$ unit $/ \mathrm{ml}$. Table 1 shows the result of neuraminidase treatment to lymphocytes from cervical lymph nodes and the same treatment to guinea pig RBC. In lymph node cells, the mean \pm S.D. of the percentage of RFC before the enzyme treatment was only $0.7 \pm 0.9 \%$, and treatment with neuraminidase hardly induced increase in the number of RFC. Although much higher doses of the enzyme were used as compared with treatment of thymocytes, an exposure of guinea pig $\mathrm{RBC}$ to the enzyme could not enhance the rosette formation with rat thymocytes at all.

The sialic acid level is known to be higher in medullary thymocytes than in cortical thymocytes, and medullary thymocytes collected after cortisol administration were reported to contain as much sialic acid as peripheral lymphocytes 


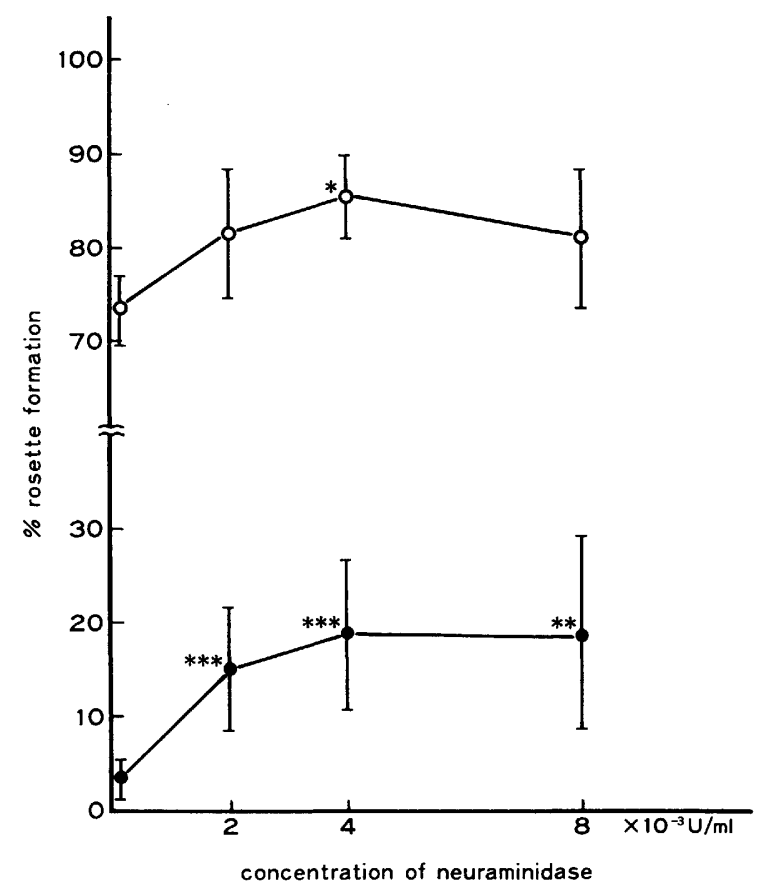

Fig. 1. Effect of neuraminidase treatment to rat thymocytes on rosette formation with guinea pig RBC. Open circles, whole thymocytes; Closed circles, medullary thymocytes collected from cortisol-treated rats.

${ }^{*} p<0.05,{ }^{* *} p<0.01,{ }^{* * *} p<0.001$

Table 1. Effect of neuraminidase treatment to lymph node cells and guinea pig RBC on rosette formation. All data obtained from three separate experiments.

\begin{tabular}{ccc}
\hline & $\begin{array}{c}\text { Concentration of } \\
\text { neuraminidase }(\mathrm{U} / \mathrm{ml})\end{array}$ & $\%$ of RFC \\
\hline Lymph node cells & 0 & $0.7 \pm 0.9$ \\
& $2 \times 10^{-3}$ & $1.5 \pm 0.7$ \\
& $4 \times 10^{-3}$ & $2.5 \pm 0.7$ \\
& $8 \times 10^{-3}$ & $1.8 \pm 0.2$ \\
\hline Guinea pig RBC & 0 & $80.5 \pm 5.7$ \\
& $8 \times 10^{-3}$ & $81.3 \pm 6.1$ \\
& $32 \times 10^{-3}$ & $77.8 \pm 5.6$ \\
\hline
\end{tabular}

Vol. 34, No. 6, 1984 
(DESPONT et al., 1975). From the result indicating that removal of sialyl residue from medullary thymocytes by neuraminidase treatment induced a significant increase in the percentage of RFC while the similar treatment of lymph node cells could not enhance the percentage, we hypothesized that there are some differences between medullary thymocytes and peripheral lymphocytes though these populations contain similar sialic acid levels, and that the tendency of increase of RFC observed in the neuraminidase-treated whole thymocytes could be ascribed to medullary thymocytes.

It was reported that the receptor of thymocytes for rosette formation was not removed by treatment with neuraminidase (ELFENBEIN and WinKELSTEIN, 1978), but enhancemental effects of rosette formation by the enzyme were not mentioned. The reason why increasing effect of the enzyme was not detected might be that they did not treat medullary thymocytes, but only the whole thymocytes. Although a similar effect of neuraminidase on rosette formation for human $\mathrm{T}$ cells and sheep RBC has been reported (BENTwICH et al., 1973, WeINER et al., 1973, GALLI and SCHLESINGER, 1976), this enhancement of RFC percentage is induced by treatment of sheep RBC with the enzyme as well as human T cells. This enhancing mechanism of neuraminidase has been explained by reduction of negative electric charge of the cell surface. However, as to rosette between rat thymocytes and guinea pig RBC, the enzyme treatment of guinea pig RBC and lymph node cells could not increase the number of RFC. Only reduction of negative electric charge of cell surface could not sufficiently account for the data presented in this paper.

It was likely that some part of the receptors for rosette formation on medullary thymocytes was masked by sialyl residue, whereas the other receptors on medullary thymocytes and on lymph node cells were masked by other substances or by much more sialyl residue. Otherwise, many parts of receptors of medullary thymocytes might change their property in the course of maturation. These results suggest that medullary thymocytes might consist of at least two subsets; i.e. one having the receptors sensitive to an exposure to neuraminidase and another insensitive to the enzyme. Further studies into the difference of these two subsets and their precise role and nature are necessary for understanding the ontogeny of rat $\mathrm{T}$ cells.

\section{REFERENCES}

Bentwich, Z., Douglas, S. D., Siegal, F. P., and Kunkel, H. G. (1973) Human lymphocytesheep erythrocyte rosette formation: Some characteristics of the interaction. Clin. Immunol. Immunopathol., 1: 511-522.

Despont, J. P., ABel, C. A., and Grey, H. M. (1975) Sialic acids and sialyltransferase in murine lymphoid cells; Indicators of $\mathrm{T}$ cell maturation. Cell. Immunol., 17: 487-494.

Elfendein, G. J. and Santos, G. W. (1978) Rosette formation between rat thymocytes and guinea pig erythrocytes requires "active" fetal calf serum. II. Characterization of the receptor-bearing thymocytes. Cell. Immunol., 37: 199-208. 
Elfenbein, G. J. and Winkelstein, J. A. (1978) Rosette formation between rat thymocytes and guinea pig erythrocytes requires "active" fetal calf serum. I. Characteristics of "active" serum factors and receptors on thymocyte and erythrocyte. Cell. Immunol., 37: 188-198.

Galli, U. and Schlesinger, M. (1976) Studies on the formation of E-rosette by human T lymphocyte and thymus cells. In: Lymphocyte and Their Cell Membrane, ed. by ScHLESINGER, M. Academic Press, London, pp. 129-139.

TAKÁCs, L., VAJdA, Z., OLÁH, I., and TöRÖ, I. (1981) Tissue localization of rat lymphocytes forming rosettes with guinea pig erythrocytes in the presence of fetal calf serum. Dev. Comp. Immunol., 5 : 157-161.

TAKEICHI, N. and BoONE, C. W. (1976) Spontaneous rosette formation of rat thymus cells with guinea pig erythrocytes. Cell. Immunol., 27: 52-57.

Weiner, M. S., Bianco, C. B., and NussenzWeig, U. (1973) Enhanced binding of neuraminidase treated sheep erythrocytes to human T lymphocytes. Blood, 42: 939-946. 